\title{
Drugs in induction and treatment of idiopathic inflammatory myopathies
}

\author{
Luca Iaccarino - Elena Bartoloni - Roberto Gerli • Alessia Alunno • \\ Simone Barsotti - Giacomo Cafaro - Mariele Gatto - Rosaria Talarico • \\ Alessandra Tripoli $\cdot$ Margherita Zen $\cdot$ Rossella Neri $\cdot$ Andrea Doria
}

Received: 24 September 2014/ Accepted: 3 October 2014/Published online: 19 October 2014

(C) Springer International Publishing Switzerland 2014

\begin{abstract}
Idiopathic inflammatory myopathies (IIM) are a rare disease; so far standardized therapy has not been adequately defined by national or international guidelines or recommendations. Corticosteroids are the mainstay of treatment, but these drugs are burdened by several side effects. Thus, additional treatment based on immunosuppressive agents, especially azathioprine, methotrexate, mycophenolate mofetil and cyclosporine, is often needed. This combinate approach both improves the disease response and allows reduction of the dosage of corticosteroids, decreasing the risk of steroid-related long-term complications. Biological agents, particularly B cell depleting agent, are emergent therapeutic tools for refractory cases. Notably, drugs currently used for the therapy of IIM or other rheumatologic and non-rheumatologic conditions can induce myopathy. Drug-induced myopathies represent a considerable part of the complex topic of muscular disorders and should be always considered in the usual diagnostic work-up of a subject with muscle disease. Several mechanisms have been advocated to explain muscular damage induced by a number of drugs and, although a recovery after drug removal is usually observed, severe or persistent myopathy may be observed following
\end{abstract}

L. Iaccarino $\cdot$ M. Gatto $\cdot$ M. Zen · A. Doria $(\bowtie)$

Rheumatology Unit, Division of Rheumatology, Department of

Medicine-DIMED, University of Padova, Via Giustiniani, 2,

35128 Padua, Italy

e-mail: adoria@unipd.it

E. Bartoloni · R. Gerli · A. Alunno · G. Cafaro

Rheumatology Unit, Department of Medicine, University of Perugia, Perugia, Italy

S. Barsotti · R. Talarico - A. Tripoli · R. Neri Rheumatology Unit, Clinical and Experimental Medicine Department, University of Pisa, Pisa, Italy the administration of some drugs, particularly in subjects with genetic predisposition. In this review the traditional and novel therapeutic approaches for patients with IIM, particularly biologics, will be discussed and an overview on drug-induced myopathies will also be provided.

Keywords Traditional therapy - Biologic therapy · Inflammatory myopathies · Non-inflammatory myopathy · Drug-induced myopathy

\section{Introduction}

Idiopathic inflammatory myopathies (IIM) are characterized clinically by weakness and low endurance of skeletal muscle and histopathologically by the presence of $\mathrm{T}$ cells, macrophages, dendritic cells, B cells and plasma cells in the muscle tissue [1]. Histopathological and immunochemical analysis of inflammatory muscular infiltrates has improved the diagnosis and the discovery of several new auto-antibodies leading to the identification of more homogeneous subsets of myositis. Notably, the increasing knowledge has been translated into new therapeutic targets in patients affected with IIM. However, several issues remain unresolved, including the absence of universally accepted guidelines for the treatment of each subset of disease, the limited number of randomized controlled trials for most of the drugs used in patients with IIM and the limited efficacy of the immunosuppressive and immunomodulatory drugs currently available in patients with inclusion body myositis (IBM).

On the other hand, muscle is often hurted by several toxic substances, some of which are used in the therapy of IIM or other rheumatologic conditions. Drug-induced myopathies, sometimes a diagnostic challenge for the 
physician, should be always considered in the usual diagnostic work-up of a subject with muscle disease.

In this review we will discuss all the therapeutic approaches currently used in the treatment of patients with IIM, particularly the new biologic drugs. An overview on drug-induced myopathies will be also provided.

\section{Drug-induced myopathies}

In the broad spectrum of non-inflammatory toxic myopathies, those induced by drugs represent one of the most frequent diagnoses to be considered in the diagnostic approach of a patient presenting with muscle pain, weakness and fatigability [2,3]. Moreover, several features make drug-induced myopathy an intriguing model used to explore pathogenesis and clinical aspects of muscle diseases. A wide spectrum of possible mechanisms has been identified to contribute to muscular damage and recent studies have allowed to gain understanding of the importance of genetic susceptibility to myotoxicity. Nevertheless, additional studies are required to investigate pathogenic mechanisms underlying drug muscular toxicity and to evaluate the role of pharmacogenomic screening in reducing the risk of drug-induced myotoxicity.

Potential agents which may induce toxic myopathy

In contrast to many other muscle diseases, drug-induced myopathy is potentially reversible if the offending drug is removed. Nevertheless, it is important to consider that certain drugs may unmask a previously unrecognized neuromuscular disorder or generate an immune response to specific muscle antigens, thus resulting in a form of toxic inflammatory myopathy. In this setting, it has been recently demonstrated that some subjects, likely with a peculiar genetic susceptibility, may develop a form of statininduced autoimmune necrotizing myopathy characterized by creatine kinase (CK) elevation, persistent and progressive muscular weakness despite drug removal and detectable circulating antibodies directed against hydroxyl-3methylglutaryl-coenzyme A reductase (anti-HMGCR) [4, 5].

Drugs may injure muscular structure via different mechanisms [6]. The most common is a form of inflammatory and necrotizing myopathy traditionally associated with statins and fibrates assumption, rarely evolving in a potentially life-threatening rhabdomyolysis, characterized by vacuolization of tubular system with intact sarcolemma and necrotic and degenerating myofibers $[2,7,8]$. Inflammatory myopathies have been reported also in patients treated with azathioprine, propylthiouracil, cimetidine and a [9]. Histological features of a mitochondrial disorder and mitochondrial DNA depletion, with severe myonecrosis supportive of a mitochondrial myopathy, have been described in patients receiving antiretroviral therapy, including zidovudine and clevudine [10]. Chronic treatment with high-dose fluorinated glucocorticoids (dexamethasone, betamethasone, triamcinolone) and, more rarely, some non-fluorinated steroids, including prednisolone, induce a classic pattern of skeletal muscle damage known as "steroid myopathy", characterized by non-specific histological features with fiber size variation, selective type 2 fiber atrophy, lack of inflammation and occasional random necrosis [6]. A peculiar histological pattern has been described in patients treated with standard doses of colchicine for prolonged periods [3]. In these patients muscle biopsy reveals a classical vacuolar microtubular myopathic pattern without necrosis or inflammation. A lysosomal vacuolar myopathy with vacuoles containing myeloid bodies may also be detected in patients chronically treated with chloroquine and, to a lesser extent, with hydroxychloroquine. In both cases, a concomitant axonal neuropathy may contribute to exacerbate muscular symptoms. Moreover, many therapeutic agents, including diuretics, laxatives and amphotericin B, may induce muscular injury indirectly by causing hypokalemia, thus causing a form of hypokalemic myopathy characterized by muscle weakness, fatigue, pain or cramps [2].

Finally, it is important to consider that drug-induced muscular toxicity may be increased by the concomitant use of other drugs or abuse of substances including alcohol, opioids and caffeine. In this context, many commonly used drugs, including verapamil, diltiazem, azithromycin, clarithromycin, cyclosporine, itraconazole and fibrates, may increase the risk of myotoxicity eventually leading to rhabdomyolysis $[6,7]$. In addition, heavy alcohol intake has been associated to a form of acute alcoholic myopathy generally leading to myoglobinuria and rhabdomyolysis with significant morbidity and mortality $[6,7]$. The presence of renal insufficiency and the concomitant use of cyclosporine and statins have been identified as significant risk factors for colchicine-induced myopathy.

\section{Clinical picture}

Drug-related myopathy may represent a potential serious medical condition, especially if the causative drug is not promptly recognized and removed. In this setting, causal relationship between muscle disorder and potential myotoxic drug should be suggested by some features, including lack of preexisting muscular symptoms, evidence of a reasonable temporal relationship between drug introduction 
and symptom appearance, lack of any other causes of myopathy and partial or complete symptom resolution following drug withdrawn. Many medications may induce or trigger myotoxicity, especially if used concomitantly.

The clinical spectrum of drug-induced muscle disorders may be extremely variable and may occur at any time following drug administration. Clinical manifestations range from benign myalgia and muscle cramps to severe acute and chronic myopathy evolving in irreversible muscle atrophy and weakness with severe disability. However, clinical picture may present some peculiar features depending on the assumed drug. In this setting, statins and other lipid-lowering medications generally induce myalgia, spasms, cramps and abnormal muscle fatigability mostly localized to the thighs and calves. Glucocorticoids may induce a progressive chronic myopathy with painless pelvic girdle muscle wasting, while colchicine may lead to a typical neuromyopathy with proximal muscle weakness, distal areflexia and minor sensory loss. A form of pseudomyasthenia with girdle muscle fatigability and diffuse pain has been described following prolonged hydroxychloroquine therapy [9]. Generally, drug-induced muscle toxicity is dose-dependent and CK concentration directly correlates with muscular damage, especially in statin-associated myopathy. Rarely, statins and, to a lesser extent, colchicine may induce a severe and potentially life-threatening myotoxicity leading to rhabdomyolysis with $\mathrm{CK}$ level elevation greater than ten times upper normal limit, skeletal muscle cell destruction, myoglobinuria and renal failure [4, 11]. Similarly, a severe form of muscular weakness and dysfunction, known as critical illness myopathy or acute quadriplegic myopathy, has been described in patients treated with high-dose corticosteroids [3]. Sepsis, heavy sedation and concomitant administration of neuromuscular blocking agents have been identified as risk factors commonly associated with this lifethreatening condition.

By definition, drug-induced myotoxicity resolves once the offending medication has been withdrawn. The time between drug removal and symptom and laboratory finding resolution varies considerably ranging from 1 week to more than 1 year. However, the course may be chronic, as observed in statin-induced necrotizing myopathy or in patients with underlying concomitant neuromuscular disorder. In this setting, a muscle biopsy should be considered in patients failing to improve or presenting persistent muscular weakness following drug removal to reveal a concomitant necrotizing autoimmune or inflammatory myopathy requiring immunosuppressive treatment.

\section{Drugs used in patients with idiopathic inflammatory myopathies}

Traditional therapy

\section{Corticosteroids}

Optimal corticosteroids dosage and treatment duration in patients with IIM is not standardized, since no placebocontrolled trial with corticosteroids has ever been carried out. High doses of corticosteroids are recommended as starting dose (prednisone or its equivalent: $0.75-1 \mathrm{mg} / \mathrm{kg}$ / day), which should be maintained for 4-12 weeks [12]. Indeed, it has been observed a maximal improvement of muscle function after an average of 12 weeks of high dose steroids. Dose tapering usually begins after 1 month and is about $10-20 \%$ of the daily dose every month until the lowest possible dosage that controls the disease is achieved (usually 5-15 mg/day). Response to treatment and outcome are influenced by early treatment. Nevertheless, corticosteroids should be carefully used, since steroidinduced side effects are major causes of disability in patients with IIM, including diabetes, hypertension, aseptic necrosis, cataracts and osteoporotic vertebral fractures [13]. Noteworthy, myopathy can also be induced by longterm treatment with corticosteroids.

\section{Immunosuppressants}

Immunosuppressants are often added to corticosteroids in the treatment of patients with IIM. Evidence on the use of these drugs is low since only a limited number of doubleblind randomized controlled trials have been carried out to date, mostly in small cohorts of IIM patients. However, open label series and clinical experience suggest the early introduction of immunosuppressants, especially in severe cases with poor prognosis, in order to facilitate corticosteroids dose tapering which may help to reduce long-term corticosteroid-related side effects.

The most used immunosuppressant in IIM patients is methotrexate. Dosage is similar to that used in rheumatoid arthritis, up to $25 \mathrm{mg}$ weekly, even though the administration of higher doses was reported. Mild pulmonary involvement is not considered a contraindication for methotrexate. Azathioprine and cyclosporine are also used in patients with IIM, usually at the dosage of $1-2 \mathrm{mg} / \mathrm{Kg}$ / die and 4-6 mg/Kg/die, respectively [14].

Mycophenolate mofetil has been recently introduced in the treatment of IIM patients, allowing the reduction in corticosteroid dose. In a recent literature review including small series and case reports, mycophenolate mofetil was reported to be orally used at a dose of up to $3 \mathrm{~g}$ per day, 
leading to a muscle strength improvement in about $2 / 3$ of cases [15]. Mycophenolate Mofetil was also well tolerated.

Cyclophosphamide in combination with corticosteroids was effective on pulmonary function in patients with severe pulmonary involvement. However, cyclophosphamide $\left(1-2 \mathrm{mg} / \mathrm{kg} /\right.$ day orally or $0.75-1 \mathrm{~g} / \mathrm{m}^{2} \mathrm{IV}$ per month for 5-6 months) is usually reserved to more severe cases, due to the high frequency of side effects (haemorragic cystitis, ovarian failure, cancer induction).

\section{Intravenous immunoglobulins}

Conflicting results on the use of high dose intravenous immunoglobulins (IVIg) in patients with IIM has been reported in the literature. A double-blind, placebo-controlled, crossover trial in 15 patients diagnosed with dermatomyositis showed a significant improvement in muscle strength and neuromuscular symptoms after 3-month treatment with intravenous immunoglobulin compared with those receiving placebo [16]. Nevertheless, another randomized, double blind, placebo controlled trial using IVIg in few patients with IIM did not confirm these encouraging results [17]. In addition, an open label study carried out on 35 patients with polymyositis showed a disease improvement in over $70 \%$ of cases, but seven of the 25 patients who improved relapsed after an average time of 17.1 months (range 4-23 months) from the discontinuation of IVIg [18]. Thus, due to the high costs and the uncertain results, nowadays the use of IVIg is limited to IIM patients refractory to immunosuppressive treatment. Side effects are usually mild.

Novel therapeutic approaches in idiopathic inflammatory myopathies

Potential molecular target for novel therapeutical approaches in patients with IIM are directed against B and T cells, and cytokines (Table 1). These new molecules are actually reserved to patients who fail to respond to traditional treatments [19].

\section{Anti B cell therapy}

A critical role of $\mathrm{B}$ cells in the pathogenesis of IIM is supported by the presence of autoantibodies but also by the identification of B cells infiltrates in affected muscles.

Rituximab is a chimeric monoclonal antibody directed against CD20, a protein expressed on B cells surface. The effectiveness of rituximab in IIM has been suggested by several case reports and case series of patients with refractory disease and by one randomized controlled trial.

Data from the national French registry [20] showed that rituximab was well tolerated and effective in $53 \%$ of patients (16/30) with no difference between anti-Jo1 positive and negative patients. Furthermore, the Spanish BIOGEAS registry [21] reported a good balance between efficacy and adverse events with a complete/partial response in $17 / 20$ patients $(85 \%)$. Particularly, the response was better in patients with muscular (94\%), pulmonary $(75 \%)$ and cutaneous involvement (80\%). In a recent retrospective study, 8/16 patients improved after treatment without relevant adverse events and five of them remained stable over 12 months [22]. Definite conclusions were difficult to draw due the small number and heterogeneity of patients.

In a prospective, randomized, double blind trial, 163 out of 200 adult and pediatric patients $(83 \%)$ met the definition of improvement after a median follow-up of 20 weeks; in addition, a significant corticosteroid sparing effect was demonstrated [23].

Nalotto et al. [24], in a recent review, reported an overall significant improvement in about $80 \%$ of patients; however, long term remission was reported in only $4.5 \%$ of cases. In the conclusion, the authors underline the efficacy of rituximab in refractory diseases and particularly in patients with anti-synthetase syndrome. The safety profile seems favorable although severe adverse events such as opportunistic infections have been reported.

\section{Anti T cell therapy}

$\mathrm{T}$ cells are likely to play a role in the pathogenesis of IIM contributing to muscle damage and chronic inflammation. They cause direct muscular cytotoxicity on MHC class I positive fibers but also enhance pro-inflammatory cytokines. Moreover, Th17 cells can produce interleukin (IL)-17 which has a role in the migration, differentiation and maturation of inflammatory cells. A T cell subset, CD28 ${ }^{\text {null }}$, dominates the $\mathrm{T}$ cells infiltrate both in involved muscles and in peripheral blood of IIM patients and are thus an emergent therapeutic target in the treatment of refractory myositis.

A proof-of-principle study among 13 IBM patients suggested that alemtuzumab, a monoclonal antibody which target CD52, a protein which is expressed on CD28 ${ }^{\text {null }} \mathrm{T}$ cells, is able to deplete peripheral blood lymphocytes and may reduce endomysial inflammation. It was reported to be beneficial altering natural course of disease [25] but, although preliminary results are encouraging, further investigations are needed to confirm efficacy and safety of this treatment.

Abatacept, a fully human fusion protein between the Fc portion of IgG1 and the cytotoxic T lymphocyte antigen 4 (CTLA-4), can block co-stimulatory signals requested for full $\mathrm{T}$ cell activation. Few case reports highlight the potential value of abatacept as a novel approach in refractory IIM [26]. 
Table 1 Potential target for novel therapeutical approaches for patients with IIM (modified from [19])

\begin{tabular}{|c|c|c|c|}
\hline & Target & Relevance for IIM & Actual data \\
\hline $\mathrm{B}$ cells & CD20+ B cells & $\begin{array}{l}\text { B cells and CD138+ plasma cells are found in muscle } \\
\text { tissue. B cells producing autoantibodies and cytokines } \\
\text { can also act as antigen presenting cells }\end{array}$ & $\begin{array}{l}\text { Some studies [20-22] and a RCT [23] report an } \\
\text { improvement after rituximab (chimeric antiCD20 } \\
\text { monoclonal antibody) treatment in muscle } \\
\text { performance, CK levels, antibody levels and } \\
\text { stabilization of ILD }\end{array}$ \\
\hline \multirow[t]{2}{*}{$\mathrm{T}$ cells } & $\mathrm{CD} 28^{\text {null }} \mathrm{T}$ cells & $\begin{array}{l}\text { Persistence in peripheral blood and muscle infiltrates } \\
\text { even after prednisone treatment. CD } 28^{\text {null }} \text { are } \\
\text { cytotoxic in close proximity to muscle }\end{array}$ & $\begin{array}{l}\text { No data available. However, alemtuzumab (targeted } \\
\text { antiCD52, present on CD28 }{ }^{\text {null }} \mathrm{T} \text { cells) seems to be } \\
\text { efficacy in IBM patients [15] }\end{array}$ \\
\hline & $\begin{array}{l}\mathrm{T} \text { cells } \\
\text { costimulations }\end{array}$ & $\begin{array}{l}\text { CD28 is constitutively present on } \mathrm{T} \text { cells and } \\
\text { interaction with CD80 causes } \mathrm{T} \text { cells activation }\end{array}$ & $\begin{array}{l}\text { Abatacept (a fusion protein of the Fc region of the IgG1 } \\
\text { fused to the extracellular domain of CTLA-4) seems } \\
\text { to be effective in IIM patients in case reports and case } \\
\text { series [26] }\end{array}$ \\
\hline \multirow[t]{4}{*}{ Citokines } & TNF- $\alpha$ & $\begin{array}{l}\text { TNF- } \alpha \text { can have a direct impact on muscle function, } \\
\text { although its importance in PM and DM is not well } \\
\text { defined }\end{array}$ & $\begin{array}{l}\text { Controversial effects of anti-TNF; infliximab may } \\
\text { worsen refractory cases [27] }\end{array}$ \\
\hline & IL-1 & $\begin{array}{l}\text { IL- } 1 \alpha \text { and } \beta \text { are consistently expressed in muscle tissue } \\
\text { of PM and DM. IL- } 1 \text { induces transmigration of } \\
\text { immune cells to the site of inflammation }\end{array}$ & $\begin{array}{l}\text { Case reports and case series showed a clinical response } \\
\text { to IL-1 blockade with anakinra (IL-1 receptor } \\
\text { antagonist) [28] }\end{array}$ \\
\hline & IL-6 & $\begin{array}{l}\text { IL-6 is expressed in muscle tissue in some PM and DM } \\
\text { patients. It supports the growth of B cells, is an } \\
\text { antagonist to regulatory T cells promoting the } \\
\text { cytotoxic T cells }\end{array}$ & $\begin{array}{l}\text { Two case reports on the successful treatment of PM } \\
\text { with tocilizumab (humanized anti-IL-6 receptor } \\
\text { antibody). Efficacy in experimental animal model of } \\
\text { myositis [29] }\end{array}$ \\
\hline & IFN type I & $\begin{array}{l}\text { IFNs up-regulate MHC class I and class II and control } \\
\text { function and regulation of T cells. Anti Jo-1-positive } \\
\text { sera induced IFN-a production }\end{array}$ & $\begin{array}{l}\text { Monoclonal antibodies targeting IFN- } \alpha \text { and IFN- } \gamma \text { are } \\
\text { being investigated in connective tissue diseases. } \\
\text { Sifalimumab (anti-IFN } \alpha \text { monoclonal antibody) was } \\
\text { well tolerated in a phase I clinical trial of patients } \\
\text { with PM and DM [30] }\end{array}$ \\
\hline
\end{tabular}

$T N F$ - $\alpha$ tumor necrosis factor- $\alpha, I L-1$ interleukin-1, $I L-6$ interleukin- $6, I F N$ interferon, $I I M$ idiopathic inflammatory myopathies, $P M$ polymyositis, $D M$ dermatomyositis, IBM inclusion body myositis, $R C T$ randomized controlled trial, $C T L A-4$ cytotoxic T lymphocyte antigen 4 , $C K$ creatine kinase, $I L D$ interstitial lung disease, $M H C$ major histocompatibility complex

\section{Anti cytokine therapy}

Inflammatory cells in the muscle tissue may also damage muscles releasing cytokines, which may have a pathogenic role in IIM. These cytokines can be potentially used both as disease biomarkers and therapeutic targets. However, the evidence of efficacy of anti-cytokine therapy is very limited, since only few case report and small series are available.

Tumor necrosis factor alpha $(\mathrm{TNF} \alpha)$ is upregulated in patients with IIM and can have a direct impact on muscle function; however, its importance in polymyositis and dermatomyositis is still elusive. Small uncontrolled case series where anti-TNF $\alpha$ drugs, etanercept and infliximab, were administered in IIM patients, showed controversial results; further, several cases of anti-TNF $\alpha$ induced myositis are reported and, thus, the use of antiTNF $\alpha$ should not be encouraged in the treatment of IIM [27].

IL $1 \alpha$ and $1 \beta$ are consistently over-expressed in myositis patients and may increase the expression of proinflammatory genes and adhesion molecules. Treatment with the IL-
1 receptor antagonist (anakinra) showed encouraging results in a case series in which patients with more severe extra-muscular involvement at baseline responded better than those with milder involvement [28].

IL-6 has been found to be over-expressed in the sera and muscular infiltrates of IIM patients and plays a role in muscle wasting. IL-6 acts inducing B and CD4 and CD8 positive $\mathrm{T}$ cell differentiation. IL- 6 blockade with tocilizumab (humanized anti-IL6 antibody) was proposed as an innovative approach for the treatment of refractory IIM. Tanaka et al. [29] recently published the case of two antiJo1 positive PM patients, refractory to steroid and conventional immunosuppressive treatment, who rapidly responded to tocilizumab.

Type I interferons (IFN) are strong inducers of class I and class II MHC molecules, which are overexpressed in muscle fibers of IIM patients. Immunomodulatory function include the control of Th1/Th2 function and the regulation of $\mathrm{T}$ cell cytotoxic and memory activity. A reduced level of multiple $\mathrm{T}$ cell-associated proteins after sifalimumab (anti-IFN- $\alpha$ monoclonal antibody) suggests a suppressive effect of blocking type I IFN signaling on T cells activation 
that may be lead to a reduction in $\mathrm{T}$ cell infiltration in the muscle of IIM patients [30].

Conlict of interest Luca Iaccarino, Elena Bartoloni, Roberto Gerli, Alessia Alunno, Simone Barsotti, Giacomo Cafaro, Mariele Gatto, Rosaria Talarico, Alessandra Tripoli, Margherita Zen, Rossella Neri and Andrea Doria declare that they have no conflict of interest.

Human and animal rights All procedures performed in studies involving human participants were in accordance with the ethical standards of the institutional and/or national research committee and with the 1964 Helsinki declaration and its later amendments or comparable ethical standards.

Informed consent The study was approved by the Local Ethics Committee and informed consent was obtained from all patients, in compliance with the Helsinki Declaration.

\section{References}

1. Iaccarino L, Ghirardello A, Bettio S, Zen M, Gatto M, Punzi L, Doria A (2014) The clinical features, diagnosis and classification of dermatomyositis. J Autoimmun 48-49:122-127

2. Baer A, Wortmann R (2013) Noninflammatory myopathies. Rheum Dis Clin N Am 39:457-479

3. Teener J (2012) Inflammatory and toxic myopathy. Semin Neurol 32:491-499

4. Mohassel P, Mammen A (2013) The spectrum of statin myopathy. Curr Opin Rheumatol 25:747-752

5. Mohassel P, Mammen A (2013) Statin-associated autoimmune myopathy and anti-HMGCR autoantibodies. Muscle Nerve 48:477-483

6. Owczarek J, Jasińska M, Orszulak-Michalak D (2005) Druginduced myopathies. An overview of the possible mechanisms. Pharmacol Rep 57:23-34

7. Mastaglia F, Needham M (2012) Update on toxic myopathies. Curr Neurol Neurosci Rep 12:54-61

8. Padala S, Thompson P (2012) Statins as a possible cause of inflammatory and necrotizing myopathies. Atherosclerosis 222:15-21

9. Guis S, Mattei J, Bendahan D (2013) Toxic myopathies. Joint Bone Spine 80:231-233

10. Finsterer J, Segall L (2010) Drugs interfering with mitochondrial disorders. Drug Chem Toxicol 33:138-151

11. Hohenegger M (2012) Drug induced rhabdomyolysis. Curr Opin Pharmacol 12:335-339

12. Oddis CV, Medsger TA Jr (1988) Relationship between serum creatine kinase level and corticosteroid therapy in polymyositisdermatomyositis. J Rheumatol 15:807-811

13. Zen M, Canova M, Campana C, Bettio S, Nalotto L, Rampudda $M$ et al (2011) The kaleidoscope of glucorticoid effects on immune system. Autoimmun Rev 10:305-310

14. Briani C, Doria A, Sarzi-Puttini P, Dalakas MC (2006) Update on idiopathic inflammatory myopathies. Autoimmunity 39:161-170

15. Iaccarino L, Rampudda M, Canova M, Della Libera S, SarziPuttini P, Doria A (2007) Mycophenolate mofetil: what is its place in the treatment of autoimmune rheumatic diseases? Autoimmun Rev 6:190-195
16. Dalakas MC, Illa I, Dambrosia JM, Soueidan SA, Stein DP, Otero C et al (1993) A controlled trial of high-dose intravenous immune globulin infusions as treatment for dermatomyositis. N Engl J Med 329:1993-2000

17. Cherin P, Piette JC, Wechsler B, Bletry O, Ziza JM, Laraki R et al (1994) Intravenous gamma globulin as first line therapy in polymyositis and dermatomyositis: an open study in 11 adult patients. J Rheumatol 21:1092-1097

18. Cherin P, Pelletier S, Teixeira A, Laforet P, Genereau T, Simon A et al (2002) Results and long-term followup of intravenous immunoglobulin infusions in chronic, refractory polymyositis: an open study with thirty-five adult patients. Arthritis Rheum 46:467-474

19. Venalis P, Lundberg IE (2014) Immune mechanisms in polymyositis and dermatomyositis and potential targets for therapy. Rheumatology (Oxford) 53:397-405

20. Couderc M, Gottenberg JE, Mariette X, Hachulla E, Sibilia J, Fain $O$ et al (2011) Efficacy and safety of rituximab in the treatment of refractory inflammatory myopathies in adults: results from the AIR registry. Rheumatology (Oxford) 50:2283-2289

21. Ramos-Casals M, García-Hernández FJ, de Ramón E, Callejas JL, Martínez-Berriotxoa A, Pallarés L et al (2010) Off-label use of rituximab in 196 patients with severe, refractory systemic autoimmune diseases. Clin Exp Rheumatol 28:468-476

22. Muñoz-Beamud F, Isenberg DA (2013) Rituximab as an effective alternative therapy in refractory idiopathic inflammatory myopathies. Clin Exp Rheumatol 31:896-903

23. Oddis CV, Reed AM, Aggarwal R, Rider LG, Ascherman DP, Levesque MC et al (2013) Rituximab in the treatment of refractory adult and juvenile dermatomyositis and adult polymyositis: a randomized, placebo-phase trial. Arthritis Rheum 65:314-324

24. Nalotto L, Iaccarino L, Zen M, Gatto M, Borella E, Domenighetti $M$ et al (2013) Rituximab in refractory idiopathic inflammatory myopathies and antisynthetase syndrome: personal experience and review of the literature. Immunol Res 56:362-370

25. Dalakas MC, Rakocevic G, Schmidt J, Salajegheh M, McElroy B, Harris-Love MO et al (2009) Effect of alemtuzumab (CAMPATH 1-H) in patients with inclusion-body myositis. Brain 132:1536-1544

26. Kerola AM, Kauppi MJ (2014) Abatacept as a successful therapy for myositis-a case-based review. Clin Rheumatol. doi:10.1007/ s10067-014-2507-4

27. Lazarou IN, Guerne PA (2013) Classification, diagnosis, and management of idiopathic inflammatory myopathies. J Rheumatol 40:550-564

28. Zong M, Dorph C, Dastmalchi M, Alexanderson H, Pieper J, Amoudruz P et al (2014) Anakinra treatment in patients with refractory inflammatory myopathies and possible predictive response biomarkers: a mechanistic study with 12 months followup. Ann Rheum Dis 73:913-920

29. Tanaka T, Narazaki M, Ogata A, Kishimoto T (2014) A new era for the treatment of inflammatory autoimmune diseases by interleukin-6 blockade strategy. Semin Immunol 26:88-96

30. Higgs BW, Zhu W, Morehouse C, White WI, Brohawn P, Guo X et al (2014) A phase 1b clinical trial evaluating sifalimumab, an anti-IFN- $\alpha$ monoclonal antibody, shows target neutralisation of a type I IFN signature in blood of dermatomyositis and polymyositis patients. Ann Rheum Dis 73:256-262 